\title{
POSSIBILIDADES DA ANÁLISE DA PRODUÇÃO ESCRITA EM UM GRUPO DE TRABALHO COM PROFESSORES DE MATEMÁTICA
}

\author{
Darlysson Wesley da Silva* \\ João Ricardo Viola dos Santos ${ }^{* *}$
}

\section{Resumo}

O objetivo deste artigo é investigar possibilidades da análise da produção escrita em um grupo de trabalho com professores de Matemática, tomando como principais referências teórico-metodológicas o modelo dos campos semânticos (LINS, 2012) e a Análise da Produção Escrita (BURIASCO, 2004). Por meio de uma abordagem de pesquisa qualitativa, produzimos nossos dados a partir de gravaçóes de oito encontros com professores que ensinam Matemática. Com intenções de discutir as demandas da prática docente, pudemos destacar algumas consideraçóes na direção de que um grupo de trabalho com professores que ensinam Matemática pode oferecer condições para que estes construam diversificadas estratégias didático-pedagógicas personalizadas aos seus alunos e aos contextos político e social a partir de situações das suas experiências.

Palavras-chave: Demandas da prática docente. Desenvolvimento profissional de professores. Produções de significados. Modelo dos campos semânticos.

\section{INTRODUÇÃo}

Se, por um lado, na pesquisa em Educação Matemática, existem vários trabalhos que investigam aspectos relacionados ao ensino e à aprendizagem de alunos por meio de seus registros escritos (BURIASCO, 2004; VIOLA DOS SANTOS; BURIASCO; CIANI, 2008; OLIVEIRA; PALIS, 2012), por outro, temos ainda poucos trabalhos que investigam possibilidades da análise da produção escrita na formação continuada de professores de Matemática. Com isso, podemos produzir alguns questionamentos sobre essas possibilidades: que interações são produzidas quando professores analisam produções escritas em grupos de trabalhos? Quais estratégias didático-pedagógicas podem ser discutidas nesses espaços? Quais são as contribuições da análise da produção escrita para formação continuada de professores de Matemática?

Nesse ensejo, o objetivo deste artigo é investigar possibilidades da análise da produção escrita em um grupo de trabalho com professores de Matemática. Produzimos nossos dados a partir de gravaçôes (áudio e vídeo) de oito

Mestre em Educação Matemática pela Universidade Federal de Mato Grosso do Sul (UFMS). Professor da Faculdade Maurício de Nassau Aracaju (SE). E-mail: darlyssonwesley@hotmail.com

Doutor em Educação Matemática pela Universidade Estadual Paulista (UNESP). Professor do Programa de Pós-Graduação em Educação Matemática (Mestrado e Doutorado) do Instituto de Matemática da Universidade Federal de Mato Grosso do Sul (UFMS). E-mail: joao.santos@ ufms.br

Instrumento: R. Est. Pesq. Educ., Juiz de Fora, v. 20, n. 2, jul./dez. 2018 
encontros de um grupo de trabalho com professores de Matemática. Nossa intenção no grupo de trabalho era discutir demandas da prática profissional dos professores por meio de produçóes escritas em matemática.

Este estudo faz parte de um projeto maior intitulado Análise da Produção Escrita como Oportunidade para o Desenvolvimento Profissional de Professores que Ensinam Matemática ${ }^{1}$. O objetivo principal deste projeto foi investigar potencialidades da análise da produção escrita como oportunidade para o desenvolvimento profissional de professores que ensinam Matemática. Dentre suas metas, as principais eram: apresentar subsídios para reestruturaçóes nos cursos de Licenciatura em Matemática; trilhar caminhos para formação continuada de professores; contribuir para sistematizaçóes a respeito dos conhecimentos adequados, necessários e específicos dos professores que ensinam Matemática.

\section{Modelo dos CAMPoS SEMÂNTICoS}

Nossa principal referência teórico-metodológica é o modelo dos campos semânticos (MCS) (LINS, 1999; 2001; 2012). A partir de algumas de suas noçóes, produzimos nossas leituras de nossos dados e apresentamos uma discussão no âmbito da formação continuada de professores de Matemática.

Ao escrevermos a respeito dessa teorização, explicitamos nossa forma particular de lê-la e apresentá-la (constituí-la e sermos constituídos). Com isso, formulamos nosso entendimento baseando nos pressupostos do autor (mais especificamente, nos pressupostos de "um" autor), buscando relaçóes com nossas constituições, nosso modo de falar do MCS. Assim, apresentamos (nos constituímos em) algumas noçóes que nos ajudaram a realizar nossas análises.

Para Lins (2012, p. 12), "conhecimento consiste em uma crença-afirmação (o sujeito enuncia algo que acredita) junto com uma justificação (aquilo que o sujeito entende como lhe autoriza a dizer o que diz)". Ao observarmos essa noção, poderíamos pensar em estruturar uma fórmula do tipo: Conhecimento = Crença-afirmação + Justificaçâa. Mesmo sabendo que conjecturar esse tipo de definição não seria uma boa escolha, tomemos como elementos-chave as parcelas do $2^{\circ}$ membro da igualdade.

A palavra composta crença-afirmaçâao nos remete às coerências, legitimidades de alguém que enuncia sobre algo que acredita. Para Lins (2012, p. 14), essa "palavra, em seu uso na teoria, concentrase em fazer o outro acreditar em algo em que você traz como legítimo". O termo coerência se comporta intrinsecamente dentro da palavra crença-afirmação, pelo fato de haver certa "regra oculta" que define seu entendimento. Uma vez que dizemos que crer é sinônimo de acreditar, nós, seres humanos, não acreditamos em coisas que não tenham alguma coerência para nosso mundo. Não nos satisfazemos em aceitar ou afirmar algo que, para nós, não tenha algum sentido. Com isso, o centro dessa discussão é que antecipamos a legitimidade de nossa crença-afirmação. Lins (2012) completa afirmando que

[...] nenhum conhecimento vem ao mundo ingenuamente. Aquele que o produz, o que enuncia, já fala em uma direção (o interlocutor) na qual o que ele diz, e com a justificação que tem, pode ser dito. [...] Não existe conhecimento implícito nem conhecimento "em ação" [...] Existe, no entanto, conhecimento terceira-pessoa: quando digo "fulano sabe que", ao observá-lo fazer algo (consertar uma bicicleta, por exemplo), sou eu o sujeito do conhecimento, quem o enuncia, o produz, e este conhecimento é sobre um outro (LINS, 2012, p. 13).

Diante disso, a justificação - elemento que completa a nossa "igualdade" - caracteriza-se da seguinte maneira:

Não é justificativa. Não é explicação para o que digo. Náo é algum tipo de conexão lógica com coisas sabidas. É apenas o que o sujeito do conhecimento 
(aquele que o produz, o enuncia) acredita que o autoriza a dizer o que diz (LINS, 2012, p. 21).

Ao observarmos a citação acima, temos uma ideia do que seria conhecimento, ao mesmo tempo em que se evidencia a noção de justificação não como justificativa ou tentativa de explicar e convencer alguém a respeito do que se fala. Justificação é o que garante, para o sujeito do conhecimento, a propriedade de enunciar determinada crença-afirmação. Deste modo, para nós, baseados no MCS, um conhecimento é uma crença-afirmação junto com uma justificação. Em nossos encontros no grupo de trabalho, esta foi uma leitura que fizemos: como os professores produzem crença-afirmaçóes junto com justificações ao analisarem produçóes escritas de alunos.

Outras duas noçóes que nos norteiam no MCS são: significado e objeto. "Significado de um objeto é aquilo que efetivamente se diz a respeito de um objeto, no interior de uma atividade. O objeto é aquilo para que se produz significado" (LINS, 2012, p.28). No MCS não se tem objeto sem antes ter uma produçáo de significado. Contudo, não se deve julgar o objeto como menos importante pelo fato de depender diretamente do significado. Lins (2012, p.29) apresenta a sua importância diretamente quando afirma: "nós constituímos objetos (instituímos, criamos, inventamos, reinventamos...) produzindo significados. São objetos que estruturam nossa cognição (que é, portanto, situada, no sentido técnico do termo)".

Outro destaque da relação entre significado e objeto é que o significado de um objeto é sempre "local". Um exemplo abordado por Lins (2012) para explicar essa afirmação se apresenta na frase: "O mundo é fragmentado". Dependendo do contexto no qual esteja essa frase, a palavra "fragmentado" pode se constituir tanto como verbo quanto como adjetivo.

Partindo dessa ideia, da relação entre significado e objeto, temos a noção de interlocutor, o que se faz primordial para os processos de produção de significados.
O interlocutor é uma direção na qual se fala. Quando falo na direção de um interlocutor é porque acredito que este interlocutor diria o que estou dizendo e aceitaria/ adotaria a justificação que me autoriza a dizer o que estou dizendo. Segundo Lins (2012, p. 19), “[...] quem fala não espera que um interlocutor responda, mas a mera existência do interlocutor (a impossibilidade da solidão) instaura a dialogia. [...] O interlocutor é um ser cognitivo ${ }^{2}$, não um ser biológico".

Uma última noção do MCS que apresentamos neste artigo é a leitura plausível, que, segundo Lins (1999, p. 93), caracteriza-se como toda "tentativa de se entender um autor, passando pelo esforço de olhar o mundo com os olhos do autor, de usar os termos que ele usa de uma forma que torne o todo de seu texto plausível”.

Ler plausivelmente o outro acontece na direção de tentar produzir com o outro, lendo como esse outro opera, quais palavras utiliza, de que modo procede em uma determinada situação. Não se trata de mostrar o que o outro não fez ou mesmo o que ele deveria ter feito. A leitura plausível é sempre tentativa, em um movimento de se produzir ao lermos o outro.

Em nossos encontros no grupo de trabalho, tentamos ler plausivelmente os processos de produçáo de significados dos professores ao analisarem produçóes escritas. Lemos os processos dos professores produzirem significados e constituírem objetos em uma direção. Como eles operam? O que produzem ao analisarem produçóes escritas?

\section{AnÁlise da PROduÇấo ESCRita}

Uma simples correção de uma atividade em sala de aula de Matemática é, para o professor, um momento de tomar decisóes frente ao modo como seu aluno lida com os enunciados. Essa atitude tão frequente em sala de aula, muitas vezes realizadas com poucas discussóes, pode ser um elemento-chave para mudanças e 
transformações nas práticas profissionais de professores de Matemática. É possível transformar simples correções de professores em movimentos interessantes de análises, nas quais possam oferecer informaçóes relevantes tanto para os professores quanto para os alunos. Buriasco (2004) afirma que

\begin{abstract}
Os registros que os alunos fazem ao resolver as questôes dão valiosas informaçôes sobre o modo como compreenderam e registraram suas ideias a respeito da situação apresentada. Tais informaçóes fornecem rico material para o professor incorporar ao seu repertório no planejamento das aulas e para orientar suas escolhas didáticas, servindo como referência para conversar sobre Matemática com o aluno (BURIASCO, 2004, p.5).
\end{abstract}

Essa autora apresenta a ideia de que a análise da produção escrita é uma estratégia para conhecer modos como alunos e professores lidam com tarefas matemáticas, as estratégias que elaboram, os procedimentos que utilizam e as respostas que apresentam. Além disso, Buriasco (2004) considera um panorama de possibilidades e pontos que podem ser tomados como base da produção escrita:

Se o aluno tenta responder o item; Se registra os
dados da questão; Qual o tipo de notação utiliza;
Quais são as características da notação; Se escolhe
um procedimento que resolve corretamente a
questão e utiliza padrão escolar; Não utiliza padrão
escolar; Desenvolve corretamente o procedimento;
Não desenvolve corretamente o procedimento;
Desenvolve corretamente mas parcialmente o
procedimento; Náo desenvolve o procedimento;
Escreve a resposta; Náo escreve a resposta; Escolhe
um procedimento que não resolve corretamente a
questão; utiliza padrão escolar; Náo utiliza padrão
escolar; Desenvolve corretamente o procedimento;
Não desenvolve corretamente o procedimento;
Desenvolve corretamente, mas parcialmente o
procedimento; Náo desenvolve o procedimento;
Escreve a resposta; Não escreve a resposta
(BURIASCO, 2004, p.6).

Analisar produçóes escritas em Matemática é uma estratégia para professores de Matemática conhecerem detalhes que envolvem os processos de produçôes de significados de alunos. Mesmo que essas produçóes nos apresentem apenas o fim de um processo, pelo registro escrito, as possibilidades de produção de leituras de caminhos, travessias e atalhos construídos pelos alunos em suas resoluçóes são de muita relevância para o trabalho pedagógico dos professores.

D’Ambrosio (2013) apresenta uma pesquisa fundamentada nos pressupostos construtivistas, concomitantemente ligada a possibilidades de estabelecer e construir fundamentaçóes teóricas para o desenvolvimento da formação dos professores a partir de produções de alunos. Nesse trabalho, a autora define seus professores como professores-pesquisadores, pois, ao assumir os aspectos defendidos pelas teorias construtivistas, esses indivíduos adotaram uma posição de analistas hermenêuticos para criação de modelos para atividades futuras a partir da Matemática dos alunos e por meio de suas produçóes escritas. Os professorespesquisadores colocaram-se em movimentos de buscar possibilidades para seus trabalhos em sala de aula a partir da própria demanda que os alunos apresentavam em suas produçóes escritas. Para D’Ambrosio, esse trabalho se tornou pertinente, uma vez que

entende-se que os professores têm acesso ao pensamento do aluno e à sua voz tanto por meio de articulaçôes orais quanto de sua produção escrita. A atitude hermenêutica, ao ler a produção escrita do aluno, é um ato de "ouvir" a voz deste, pois escrever é uma forma de comunicar ideias (D’AMBROSIO, 2013, p.251).

Ao apresentar algumas conclusôes, essa autora afirma que o trabalho do professor-pesquisador, quando assume o papel de dar voz ao aluno, proporciona uma união de elementos que instigam para possibilidades $\mathrm{e}$ desenvolvimentos de modelos da Matemática com seus alunos a partir da análise de suas produçóes escritas. Esses modelos auxiliam tanto na sustentação do seu trabalho em sala de aula quanto na geração de possibilidades de novas relaçóes para a Matemática e o ensino. 
Ciani (2012) propóe duas propostas de intervenção como subsídio operacional para a constituição de oportunidade de aprendizagem por meio da análise da produção escrita. No que se refere ao uso da análise da produçáo escrita, a autora nos mostra que ela pode proporcionar ao professor uma saída da cultura e dualidade do certo/errado, assim como também um êxodo da exclusão e competição, para u ma cultura da multiplicidade das maneiras de lidar com o conhecimento, que por sua vez está diretamente relacionado à solidariedade e à cooperação. Segundo a autora

além de se apresentar como uma estratégia para implementação da avaliação como prática de investigaçáo, a análise da produçâo escrita mostrase como um caminho para conhecer múltiplos aspectos da atividade Matemática dos alunos e também como uma possibilidade para capacitar os professores e reorientar a sua prática pedagógica (CIANI, 2012, p.43).

Com isso, uma das principais relevâncias do trabalho da autora é a de buscar conhecer sua complexidade e heterogeneidade a partir da análise da produção escrita dos alunos, respeitando as vivências e idiossincrasias de cada indivíduo.

O trabalho de Pires (2013) teve por objetivo descrever e analisar uma pesquisa com prova por fases, realizada com nove professores dos anos iniciais do Ensino Fundamental de uma escola pública municipal de Londrina - PR. De forma geral, a autora buscou analisar produçóes escritas dos professores tomando como base para investigação a ideia de reinvenção guiada $^{3}$ no âmbito da Educação Matemática Realística.

No desenvolvimento do seu trabalho, a autora utiliza as questôes da prova em fase como ponto de partida para o processo de reinvenção, proporcionando um processo em que a pesquisadora/formadora participasse como guia e mediadora das situaçóes a partir de perguntas e consideraçóes a respeito das produçóes escritas dos participantes.
Segundo Pires (2013), sua reinvenção guiada, utilizando estratégias da análise da produção escrita, pôde proporcionar aos participantes (professores de Matemática) a saída de uma posição de meras receptoras de uma Matemática pronta e acabada para uma posição de professores que desempenham um papel de agente do processo de desenvolvimento e do processo de aprendizagem. Em meio aos relatos e materiais colhidos em sua pesquisa, Pires (2013) afirma que

\begin{abstract}
A prova em fase pode provocar mudanças na maneira que os professores interpretam e analisam a produção escrita dos alunos. Esta proposta, trabalhar com provas em fase, requer muito mais do que olhar apenas a resposta do aluno. Realizar uma prova em fases exige a elaboração de perguntas que guiem o aluno no processo de ensino $\mathrm{e}$ aprendizagem. A tarefa de elaborar as perguntas é uma tarefa que exige reflexão e estudo (PIRES, 2013, p.97).
\end{abstract}

Essa autora ainda argumenta que todo esse processo de prova em fases, reinvenção guiada e perspectiva da análise da produção escrita podem proporcionar caminhos para capacitação de docentes, o que não se identifica como uma "reciclagem", mas sim como uma abertura de um leque de possibilidades para a prática docente.

Diante dessas consideraçôes, neste trabalho, tomamos a análise da produção escrita como uma estratégia para o trabalho com professores de Matemática em um grupo de trabalho. Uma estratégia que não se limita a procedimentos pré-instituídos, mas que se moldam e tomam formas nos processos, nas discussōes e nas interações de professores com registros escritos de alunos, de outros professores ou mesmo deles.

\section{Estratégia METOdológica}

Neste trabalho, realizamos uma pesquisa qualitativa, de acordo com a natureza de nossos dados e os objetivos do trabalho. Segundo Garnica (2004), uma pesquisa qualitativa tem as seguintes características: 
(a) a transitoriedade de seus resultados; (b) a impossibilidade de uma análise a priori, cujo objetivo da pesquisa será comprovar ou refutar; (c) a não neutralidade do pesquisador que, no processo interpretativo, vale-se de suas perspectivas e filtros vivenciais prévios dos quais não consegue se desvencilhar; (d) que a constituição de suas compreensóes se dá não como resultado, mas em uma trajetória em que essas mesmas compreensóes e também os meios de obtê-las podem ser (re) configuradas; e (e) a impossibilidade de se estabelecer regulamentaçóes, em procedimentos sistemáticos, prévios, estáticos e generalistas (GARNICA, 2004, p.86).

Produzimos nossos dados em áudio e vídeo durante oito encontros do nosso grupo de trabalho, no período de setembro a dezembro de 2013. Cada encontro tinha a duração aproximada de quatro horas, ocorrendo nas quartas-feiras, no período da tarde.

Utilizamos gravadores de áudio e vídeo para produzir nossos dados. Os gravadores de áudio ficaram posicionados em pontos estratégicos, focando as discussóes pontuais e individuais nos grupos menores. Utilizamos duas câmeras, uma posicionada para gravar as discussóes gerais, tendo o campo visual de todos os participantes, e outra voltada para o quadronegro, focada nas discussóes do grande grupo, no qual, em alguns momentos, os professores explicitavam algumas discussões.

Nesses oito encontros, foram discutidas possibilidades, dificuldades e potencialidades de como a análise da produção escrita pode contribuir para o desenvolvimento profissional de professores de Matemática. Ao longo dos oito encontros, oito professores de Matemática de rede pública e particular participaram do grupo de trabalho. Em nossas análises, utilizamos nomes fictícios.

As atividades foram elaboradas com a intenção de serem disparadores de discussóes das demandas profissionais dos professores. Tínhamos um roteiro predeterminado para os oito encontros que poderia ser totalmente modificado ao longo do processo. A dinâmica de trabalho do grupo era construída em momentos de discussóes em pequenos grupos, com dois ou três membros, e no grande grupo, com todos os membros, iniciando sempre os encontros com discussões em pequenos grupos e terminando no grande grupo.

Um grupo de trabalho ${ }^{4}$ constitui-se como um espaço de formações. Formaçóes dos professores da Educação Básica, professores em formação em nível de graduação e pós-graduação, bem como para professores universitários. Não se trata de um curso, nem mesmo de um grupo no qual pesquisadores, mestrandos e doutorandos aplicam suas pesquisas (quase sempre estando de fora do processo). Trata-se de um grupo que pode "dar certo", "funcionar" ou não. Um grupo de trabalho nunca é e está sempre sendo.

\section{Traços de diálogos E discussóes NO GRUPO DE TRABALHO}

Apresentamos duas situaçóes em que professores dialogam em análises que envolveram produçóes escritas. São elas: a) Quando eu paro e penso no que fiz e não nos erros e dificuldades dos meus alunos; b) Mas ainda vejo alguns problemas na questão, pois eu não esperava tantas resoluçóes diferentes dos meus alunos. Dado o escopo do artigo, esses diálogos apenas ilustram algumas análises de produçóes escritas que os professores realizaram nos encontros do grupo de trabalho.

Nossa intenção é criar um fluxo dialógico e evidenciar, com isso, a dinâmica das interações no grupo de trabalho. Os diálogos foram produzidos a partir de nossas leituras plausíveis de áudio e vídeo que gravamos dos encontros do grupo de trabalho, em que nossa intenção é deixá-los em uma plasticidade próxima às dinâmicas e interaçóes no grupo de trabalho. 
QuANDO EU PARO E PENSO NO QUE FIZ E NÁO NOS ERROS E DIFICULDADES DE MEUS ALUNOS

Em uma situação de discussão entre professores, tivemos os seguintes diálogos realizados pela professora Ane, com 19 anos de profissão, que trabalhava com

Ane: Na verdade foi assim! Eu e outro professor da nossa escola, achamos um livro na biblioteca, começamos a olhar este livro e percebemos uma crianças do Ensino Fundamental II, com o professor Marcos, com 14 anos de profissão, estudante de Pósgraduação, e o professor Paulo, 7 anos de profissão, professor universitário. Ane inicia a conversa contando de seu processo para elaborar e implementar uma atividade com seus alunos, uma das atividades realizadas pelos professores no grupo de trabalho.

situação bem parecida com uma situação que já haviamos trabalhado. Então, resolvemos montar esta questão:

Observe a seguinte sucessão de figuras, construída com palitos:
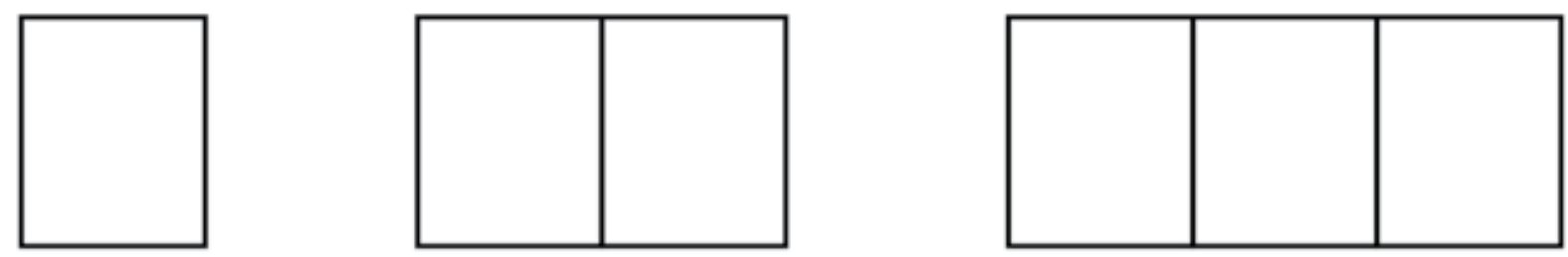

A sequência prossegue acrescentando um retângulo em cada passo. De acordo com a figura, responda às seguintes perguntas:

a) Calcular a quantidade de palitos necessários para construir a figura que ocuparia a sexta posição da sequência.

b) Calcular a quantidade de palitos necessária para construir a centésima figura da sequência.

c) Achar a fórmula que expressa a quantidade de palitos na posiçáo N.

d) É possível que, em alguma posição da sequência, a figura contenha 154 palitos?

e) Achar a fórmula que expressa a quantidade de palitos na posição de 1 até N.

f) Se eu tiver 1.550 palitos e montar a maior figura possível usando esse princípio de formação, sobrará algum palito?

Ane: Depois que aplicamos, nós percebemos que os itens " $E$ e F", eram muito dificeis para os alunos da nossa escola.

Paulo: Então, vocês elaboraram essa questão a partir de um livro? Ane: É, nós elaboramos a partir das ideias que o livro apresentava. Mesmo porque nós montamos esse ano uma atividade para trabalhar com os palitos. Como a experiência de palitos foi uma atividade que eles já vivenciaram antes, eu achava que eles teriam mais facilidade com essa.
Marcos: Eu acho que o problema pode ser esse, é que esse tipo de exercicio pode ser novo para eles, pois os mesmos não estão muito habituados com esse trabalho. Eles meio que tem que sair do "O" (zero) e se virar por conta própria, ou seja, não é um simples efetue ou calcule a conta.

Ane: Então, na verdade, nós entramos com uma proposta nova.

Marcos: É, eu sei, mas eu acho que precisa de um tempo para adaptação dessa proposta nova. E não se deve assustar caso a coisa der 
errado, porque imagine assim, você passou sete anos fazendo a mesma proposta e do nada você muda, do mesmo jeito que você vai precisar de um tempo para se adaptar, o aluno também vai precisar.

Ane: Acho que concordo. Quando nós elaboramos, ficamos tão empolgados, maravilhados, só que no desenvolver das atividades é que percebemos que alguns problemas podem existir e emergir. Então, foi dai que comecei a pensar se realmente eu fiz uma questão legal para meus alunos.

Paulo: E como foi o processo de elaboração dessa atividade? Conte-nos mais.

Ane: Então! Na verdade, eu já estava assim, quase me estressando, me descabelando, porque eu falava para o outro professor: "Eu quero fazer uma nova situação". Ele ficava meio assustado, até porque eu já pesquisava em várias fontes, blogs, essas coisas e não achava nada. E, ainda, o livro didático era sempre calcule e resolva. Dai nós estávamos estudando o livro de álgebra e encontramos uma situação igualzinha à do palito. Então nós fizemos as adaptaçooes dessas atividades dos palitos que nós encontramos no livro, que é só de práticas.

Paulo: Ela já estava desse jeito “ $a, b, c, d, e$ ” ou vocês inseriram na questão?

Ane: Nâo, nós inserimos sim.

Paulo: Em quais alternativas vocês inseriram?

Ane: Por exemplo, ela só vinha falando assim: "Calcule a quantidade necessária para construir a $6^{a}$, a $77^{a}$ e a $8^{a}$ ". Ai eu falei, não, vamos trabalhar com uma e criar outras.

Paulo: Mas teve algum motivo para você só colocar uma ao invés de pedir a $6^{a}$, a $7^{a}$ e a $8^{a}$ ? Vocês pensaram assim?

Ane: Não, não pensamos.

Marcos: Bom, eu acho que a ideia é que, depois que ele acha a primeira, a $7^{a}$ e $8^{a}$ são bastante simples.

Ane: É porque depois é só acrescentar.

Marcos: É isso mesmo, e como é $6^{a}$ e $7^{a}$ ele pode fazer sem calcular.

Ane: Então, exatamente, nós pensávamos que eles poderiam fazer tudo em forma de desenho.

Paulo: Vocês acham que eles iriam acrescentar?

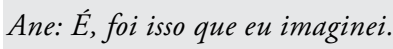

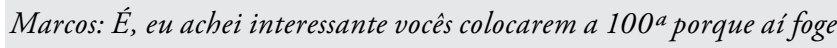
do desenho. Opa! Ai já aperta um pouco. Achei legal isso ai.

Paulo: Então a relação para que o enunciado tenha $6^{a}$, $7^{a}$ e $8^{a} e^{a}$ justamente para ele ter a ideia de generalização?

Ane: Então, foi exatamente isso que depois nós ficamos pensando se realmente era isso que deveriamos ter colocado. Porque poderia ser que, se deixássemos eles sozinhos, os mesmos poderiam ter observado que era só acrescentar três palitos.

Paulo: Você acha esse tipo de atividade, essa discussão da temática sempre acontece na aula de vocês ou vocês propuseram uma coisa que os alunos não estão acostumados a fazer?

Ane: Ah professor, depende muito, sabe por quê?? Porque assim, eu faço... o outro professor também faz... mas outros colegas não fazem.

Paulo: Entendi. Então na sua aula, isso é uma atividade comum. Eles estão acostumados a trabalhar com atividades como essa?

Ane: Então, esse ano nós começamos! Por isso eles ainda não têm costume com essa abordagem. É como o professor Marcos falou, essa é uma ideia de retorno a longo prazo. Na verdade, seria trabalhar já desde o $6^{\circ}, 7^{\circ}$, pois quando eles chegassem no $8^{\circ}$ já estariam um pouco mais maduros com esse tipo de abordagem.

Marcos: Ai sim será comum, mas o comum que o Paulo que dizer não é no sentido de se trabalhar todo dia, mas sim de fazer abordagens em alguns momentos.

Ao nos depararmos com as falas dos professores, percebemos primeiramente o interesse e empenho da professora Ane em elaborar aquela questão. Vemos que ela realmente se apresenta de maneira aberta para o desenvolvimento de atividades, do ponto de vista dela, diferenciadas para seus alunos.

O espaço de discussão do grupo de trabalho para a professora Ane fica evidenciado nesse diálogo. Ter à disposiçáo professores para conversarem sobre suas propostas, angústias e implementaçóes é uma característica destacável desse espaço de formação, não muito comum nos espaços escolares.

Observamos, em seu processo de produção de significado, o fato de Ane perceber que seus alunos tiveram muitas dificuldades neste problema, mesmo ela tendo já abordado atividades semelhantes com palitos. Isso causou uma preocupação em relação ao seu processo de elaboração das atividades. Diante disso, um ponto que achamos interessante foi sua atitude de repensar, refletir a respeito do problema que elaborou junto com seu amigo e não colocar a culpa pelas dificuldades em seus alunos.

Outro ponto que contribuiu também para que a professora Ane pensasse sobre a proposta foi a fala do professor Marcos em relaçâo a uma "paciência histórica" do professor. Para o professor Marcos, realizar 
implementaçóes de novas propostas requer um pouco de reflexão e amadurecimento da proposta por parte do docente. $\mathrm{Na}$ sua forma de pensar, o professor Marcos fala de uma característica que os professores em sala de aula poderiam refletir: a "paciência", sendo que ela não se apresenta por esperar que as coisas aconteçam, mas sim uma paciência relacionada ao trabalho dedicado e contínuo que o professor deve ter com seu aluno ao realizar tais abordagens.

Percebemos que, ao falar com a professora Ane, o professor Marcos destaca também que essas práticas não são dificuldades apenas dos alunos, mas também dos professores e de sua formação docente. Para Marcos, as relaçóes docentes sempre devem estar atreladas ao tempo e espaço, e que, para alcançar determinado objetivo, é necessário que os professores tenham uma determinada "dose de paciência", uma ponderação relacionada à situação que esteja sendo vivenciada.

Ao longo dessas e outras discussões, problematizamos a escrita do enunciado desta atividade, em específico a escrita de N (maiúsculo) palitos. Nossas análises, neste ponto, são específicas para discorrer sobre a importância de analisar produçóes escritas, neste caso, a de um professor sobre sua própria elaboração de atividades, com outros professores em um grupo de trabalho. O que nos chamou atenção foi o olhar de Ane para o seu próprio trabalho, seu cuidado com cada item do problema elaborado (que depois foi transformado), saindo de uma perspectiva global, em "pegar" problemas em livros para aplicar com os alunos, para uma perspectiva particular, em que discute cada parte do enunciado do problema, levando em consideração os processos de produção de significados de seus alunos.

\section{Mas eu ainda Vejo alguns PROBlemas NA QUESTÁO, POIS NÃO ESPERAVA TANTAS RESOLUÇÓES DIFERENTES DOS MEUS ALUNOS}

Duas semanas se passaram desde o primeiro encontro. Neste, agora, os professores trariam para nossa discussão um problema que eles implementaram e utilizaram com seus alunos. Trata-se da questão do carteiros:

Um carteiro entregou 100 telegramas em 5 dias. A cada dia, a partir do primeiro, entregou 7 telegramas a mais que no dia anterior. Quantos telegramas entregou em cada dia?

Paulo: Bom, pessoal, boa tarde a todos. Como haviamos combinado no último encontro, vocês trabalhariam com seus alunos aquela questão do carteiro. A partir disso, focariamos as discussöes das produçōes escritas de seus alunos diante do problema proposto por nós.

Sérgio: A gente fez uma categorização aqui, até porque achamos melhor assim para poder focar a discussão da atividade. Com isso, a gente pode fazer um desenvolvimento em cima das categorias que elaboramos. A gente quer fazer assim porque nas categorias dá pra abranger diversas consideraçōes. Mas cada grupo define a sua categoria, não queremos que todos sigam igual ao da gente. Então fizemos uma divisão em três: a) os que se aproximaram da interpretação padrão do exercício; b) o que saiu totalmente fora; $e c$ ) alguns que julgamos medianos.

Os professores se organizaram em pequenos grupos e discutiram sobre as produçôes de seus alunos. Logo, as discussóes foram realizadas no grupo como um todo.

Ruan: Bom, o primeiro raciocinio que eu tive quando vi o enunciado foi que o total de telegramas era 100 e isso era fechado. Contudo, vendo os exemplos de resoluçôes apresentados por alguns de meus alunos e depois de algumas discussóes em grupo e uma análise da questão, percebi que esse enunciado não é tão objetivo assim. Ele é subjetivo e aberto, então oferece margem a diversos raciocinios. Tentando interpretar algumas resoluçôes que meus alunos fizeram, tive a ideia de que o total de cartas nos cinco dias era 100. E isso era fechado pra mim. Outra ideia que tive foi a relação dos "7 a mais a partir do primeiro dia". Então vendo algumas hipóteses, temos que o aluno poderia pensar 100 no primeiro dia, então no segundo dia aumentou mais 7 , indo assim para 107, e no enunciado não diz que o total tinha que manter o total anterior. Então, um aluno meu fez uma resolução que se relacionava com isso, ou seja, abria margem para pensar diferentes totais de cartas entregues ao longo dos cinco dias. Outra resolução foi a questão da média. Então, o aluno pegou o 100 e dividiu em 5 dias, o que resultou 
em 20 por dia. No primeiro dia partiu desses 20 , consequentemente no segundo dia foi pra 27, 34 no terceiro, 41 no quarto dia e 48 no quinto dia. Esse daqui foi outro raciocínio.

Paulo: E eles argumentavam bastante em cima disso?

Ruan: Exatamente! Pelo fato de o enunciado da questão não ser especifico em relação à quantidade de telegramas e à quantidade de dias, então eles argumentaram: "Mas qual que é o correto?" Daí eu falei: "O correto é aquilo que você conseguir ver." Então eles se desenvolveram de acordo com o raciocínio de cada um.

Carlos: Depois você deu a devolutiva pra eles?

Ruan: Não! Eu só disse o seguinte: "O correto é aquilo que você enxergar." E cada um desenvolveu, até porque eu não queria dar tendência ao resultado pra ninguém. Então, isso gerou uma discussão entre eles. Era perceptivel a relação de disputa entre os alunos para saber quem estava certo. Porém, cada um teve um argumento que, a meu ver, dentro da lógica deles, não estava errado.

Paulo: Só para ressaltar, essa questão foi revisada por uma banca examinadora e selecionada em meio a tantas outras para uma aplicação em uma prova de avaliação em massa, ou seja, ela teve um crivo criterioso para que ela fosse escolhida.

Ruan: Hum...! Mas ainda vejo alguns problemas, pois eu não esperava tantas resoluçöes diferentes dos meus alunos, e que por sinal muitas me surpreenderam.

Esse diálogo entre professores no grupo de trabalho explicita uma questão de suma importância na prática profissional dos professores: desconfiança dos problemas, exercícios em livros, apostilas etc. Em nossa leitura, o processo de produção de significados do professor Ruan foi de que, pelas diferentes respostas de seus alunos, ele se colocou em um movimento de questionar o enunciado do problema. Vale ressaltar que, no encontro anterior, Ruan resolveu o problema, discutiu com outros professores e nenhuma dessas discussóes foi produzida por ele.

Um fato que nos chamou atenção foi a resposta que Ruan apresentou para um de seus alunos quando este perguntou "Mas qual é o correto?" e ele respondeu: "O correto é aquilo que você enxergar". Isso nos chamou atenção, pois uma das discussóes realizadas no grupo era tentarmos, sempre que possível, sair da dicotomia acerto e erro, na intençấo de colocar os alunos a elaborarem conjeturas, modos de interpretação, outras lógicas nas resoluções dos problemas. Como é possível interagir com os alunos quando fugimos dos discursos: "Ah, aqui você está errado. Tá tudo certo, meus parabéns". Ruan não apenas permitiu como também incentivou que seus alunos pudessem resolver o problema do modo como eles o aceitariam como correto. Os alunos de Ruan produziram crenças-afirmações e justificaçóes em direções diferentes da que o próprio Ruan teria produzido para o problema do carteiro.

Essas situações e os diálogos entre os professores no grupo de trabalho explicitam, mesmo que em parte, algumas possibilidades da análise da produção na formação continuada de professores. Ao longo dos oito encontros, notamos outros modos de produzir significados em relaçáo aos modos dos professores lerem seus alunos. Ao final dos encontros, eles falavam de maneira mais particular e singular de seus alunos; por exemplo, a fala do professor Carlos: "o aluno que se relaciona com o professor, que tem sua relação com o conteúdo e está inserido em um determinado contexto social".

Durante os encontros, notamos que os professores construíram alguns pressupostos pedagógicos da importância de fazer com que seus alunos falem a respeito de seus modos de produzir significados. Também construíram atitudes de ler esses alunos pelo que eles falam e fazem, tentando propor outros olhares, outras resoluções. Acreditamos que essas construçóes foram impulsionadas pelas análises de produçóes escritas, visto que, pela permanência do registro escrito, os professores puderam falar, pensar, escutar um colega, discordar ou concordar, sair do encontro, ir para sua sala de aula e fazer com que todas aquelas discussóes pudessem ser colocadas em cheque ou mesmo comprovadas pelas suas vivências, voltar para o grupo e compartilhar com colegas implementaçôes, dificuldades, angústias, possibilidades... 


\section{CONSIDERAÇÓES FINAIS}

Ao vermos nossos movimentos analíticos, notamos que a análise da produção escrita não era o foco principal das discussóes, mas em todo o momento seus processos disparavam questionamentos, soluçóes, indagações, surpresas, afliçóes. O trabalho com análise da produção escrita na formação, a serviço de professores de Matemática, mostra-se como uma possibilidade não só apenas de formação de professores, mas também de discussōes sobre Educação Matemática. Ao longo dos encontros, várias discussões políticas, econômicas e culturais apareceram, os papéis e efeitos das avaliaçóes externas, a exclusão que é feita na escola pelas correçóes das provas, a falta de tempo para o professor atender com cuidado e em detalhes os processos de produção de significados dos alunos.

Outro ponto que está ligado diretamente ao movimento da análise da produçáo escrita é o modelo dos campos semânticos, outro pano de fundo deste trabalho. No grupo de trabalho, nossa intenção não era detalhar suas noçóes. Entretanto, ao utilizarmos algumas noçóes, principalmente a leitura plausível, como uma estratégia para os professores lerem as produçôes escritas, notamos alguns movimentos dos professores com noçóes dessa teorização. Como Lins (2012) afirma, o MCS oferece "um quadro de referência para que se possa produzir leituras suficientemente finas de processos de produção de significados (p. 18)". Em nosso trabalho, ele nos serviu tanto para produçáo e análise dos dados quanto para a construção de atitudes políticas e pedagógicas de nossas atitudes como pesquisadores em formação, bem como professores também em formaçáo que participaram de um grupo de trabalho.

No grupo de trabalho, nossas intençóes e atitudes foram na direção de tentar entender o que acontecia conosco por meio de discussóes que tomavam como fio condutor a análise de produçôes escritas em Matemática. Deste modo, notamos que algumas características puderam ser delineadas em relação ao grupo de trabalho com professores que analisam produçóes escritas, tais como: estar junto com os professores (não apenas ser um professor formador, mas sim um professor); criar relaçóes de confiança (pois estar junto é criar laços de amizade e confiança); promover discussões abertas (pois discutir não é apenas falar sobre o que queremos, mas sim deixar que o outro fale dos seus anseios, aflições, felicidades, conquistas). Acreditamos que estar junto, ter confiança e abertura de discussóes podem se tornar algumas características da noção de grupo de trabalho.

De maneira sucinta, algumas possibilidades da análise da produção escrita em um grupo de trabalho com professores de Matemática são na direção de oferecer condiçôes para eles construírem estratégias didático-pedagógicas mais personalizadas aos seus alunos e aos contextos políticos e sociais nos quais eles estão inseridos; elaborar atividades levando em consideraçáo os modos de seus alunos produzirem significados (isso inclui possibilidades e dificuldades); leituras mais finas do que acontece em sala de aula, em específico aos modos como os alunos produzem significados de suas falas. A professora Ane, por exemplo, em uma discussão em um de nossos encontros, questiona-se: "Será que eles entenderam a mesma coisa que eu entendi disso que falei?".

A análise de produçóes escritas implementada em grupos de trabalho configura-se como uma estratégia para formação continuada de professores de Matemática, na qual o olhar para o outro, em suas singularidades, em tentativas de leituras plausíveis de seus processos de produção de significado, sem buscar a falta, ou mesmo aquilo que ele deveria falar. Lemos o outro e nos produzimos com ele por meio de suas produçóes escritas. 


\section{Possibilities OF THE ANALYSIS OF WRITTEN PRODUCTION IN A WORKING GROUP WITH MaThEMATICS TEACHERS}

\section{Abstract}

The purpose of this article is to investigate possibilities of the Analysis of Written Production in a working group with mathematics teachers taking as main theoretical-methodological references the Semantic Fields Model (Lins, 2012) and Written Production Analysis (Buriasco, 2004). Through a qualitative research approach, we produced our data from recordings of eight encounters with teachers who teach mathematics. With intentions to discuss the demands of teaching practice we could highlight some considerations in the direction that a working group with teachers who teach mathematics can offer conditions for them to build diverse didactic-pedagogical strategies customized to their students and to the political and social contexts from their experiences.

Keywords: Demands of the teaching practice. Professional development of teachers. Productions of meanings. Model of semantic fields.

\section{Posibilidades Del ANÁlisis DE LA PRODUCCIÓN ESCRITA EN UN GRUPO DE TRABAJO CON PROFESORES DE MATEMÁTICAS}

\section{Resumen}

El objetivo de este artículo es investigar posibilidades del análisis de la producción escrita en un grupo de trabajo con profesores de matemáticas tomando como principales referencias teórico-metodológicas el modelo de los campos semánticos (Lins, 2012) y el análisis de la producción escrita (Buriasco, 2004). Por medio de un enfoque de investigación cualitativa, producimos nuestros datos a partir de grabaciones de ocho encuentros con profesores que enseñan matemáticas. Con intenciones de discutir las demandas de la práctica docente pudimos destacar algunas consideraciones en la dirección de que un grupo de trabajo con profesores que enseñan matemáticas puede ofrecer condiciones para que éstos construyan diversificadas estrategias didáctico-pedagógicas personalizadas a sus alumnos y a los contextos político y social a partir de situaciones de sus experiencias.

Palabras clave: Demandas de la práctica docente. Desarrollo profesional de profesores. Producciones de significados. Modelo de los campos semánticos.

\section{Notas}

\footnotetext{
Projeto aprovado no Edital Universal CNPq 2012.

"Ser Cognitivo" é uma direção que se caracteriza por manifestações de pertinência, ou seja, constituído por culturas, práticas sociais. Diferentemente do ser biológico, que tem como sua manifestação de sobrevivência a alimentação e reprodução, o ser cognitivo sobrevive a partir das legitimidades das produçóes de significados. $\mathrm{O}$ princípio da reinvenção guiada leva em conta que o conhecimento não deve ser transmitido pelo professor, mas sim elaborado pelo aluno. O processo de reinvenção exige que os alunos se envolvam com situaçôes realísticas, com a intenção de matematizá-las, em um processo semelhante ao vivenciado pelo matemático profissional (PIRES, 2013, p. 24).

Essa é uma noção ainda em construção. Os trabalhos do grupo de Pesquisa e Desenvolvimento Formação, Avaliação e Educação Matemática (FAEM), em diálogo com noçóes do MCS, estão na direção de delinear algumas demarcaçôes para essa noção. Para mais informaçóes, acessar: www.faem.com.br

Esse problema é amplamente discutido nos trabalhos do Grupo de Estudos e Pesquisas em Educação Matemática e Avaliação (GEPEMA) com foco em analisar produçóes escritas de alunos. Nossa intenção em nosso grupo de trabalho foi analisar as análises dos professores em relação à análise da produção escrita de seus alunos. Para mais informaçôes dos trabalhos do GEPEMA, consultar: http://www.uel.br/grupo-estudo/gepema/
} 


\section{REFERÊNCIAS}

BURIASCO, Regina Luzia Corio. de. Análise da produçáo escrita: a busca do conhecimento escondido. In: ROMANOVSKI, J. P.; MARTINS, P. L. O.; JUNQUEIRA, S. R. A. (Org.). Conhecimento local e conhecimento universal: a aula, as aulas nas ciências naturais e exatas, aulas nas letras e artes. Curitiba. Champagnat, 2004. p. 243-251.

BURIASCO, Regina Luzia Corio. de. Análise da produção escrita como oportunidade para o desenvolvimento profissional de professor que ensinam matemática. Proposta ao CNPq. Edital Universal - MCTI/CNPq No 14/2012. Londrina: GEPEMA, 2012.

CIANI, Andréia Büttner. O realístico em questôes nãorotineiras de matemática. 2011. $166 \mathrm{f}$. Tese (Doutorado em Ensino de Ciências e Educação Matemática) -Universidade Estadual de Londrina, Londrina, 2012.

D’AMBROSIO, Beatriz Silva. O professor-pesquisador diante da produção escrita dos alunos. Revista de Educação, Campinas, v. 18, n.3, p. 249-258, set./dez. 2013.

GARNICA, Antonio Vicente Marafioti. História oral e educação matemática. In: BORBA, M. C; ARAUJO, J. L. (Org.) Pesquisa qualitativa em educação matemática. Belo Horizonte: Autêntica, 2004.

LINS, R. C. Por que discutir Teoria do Conhecimento é relevante para a Educação Matemática. In: BICUDO, M. A. V. (Org.). Pesquisa em educação matemática: concep̧̧óes e perspectivas. Rio Claro: Editora UNESP, 1999. p. 75-94.

LINS, R. C. Characterizing the mathematics of the mathematics teacher from the point of view of meaning production. In: International Congress on Mathematical Education, 10, Copenhagen, 2004. Copenhagen. Proceedings... Plenary and Regular Lectures, 2006. p.1-16.

LINS, R. C. O Modelo dos campos semânticos: estabelecimento e notas de teorizaçóes. In: ANGELO, Claudia Laus [et al.] Modelo dos campo semânticos e educaçáo matemática: 20 anos de história. Sáo Paulo: Midiograf, 2012.

OLIVEIRA, Ana Teresa de; PALIS, Gilda de La Roque. O potencial das atividades centradas em produçóes de alunos na formação de professores de matemática. Relime, v. 14, n.3, p. 335-359, 2011.

PIRES, Magna Natalia Marin. Oportunidade para aprender: uma prática da reinvenção guiada na prova em fases. 2013. 122 f. Tese (Doutorado em Ensino de Ciências e Educação Matemática) -Universidade Estadual de Londrina, Londrina, 2013.

VIOLA DOS SANTOS, João Ricardo. O que alunos da escola básica mostram saber por meio de sua produção escrita em matemática. 2007. 115 f. Dissertação (Mestrado em Ensino de Ciências e Educação Matemática) -Universidade Estadual de Londrina, Londrina, 2007.

VIOLA DOS SANTOS, João Ricardo; BURIASCO, Regina Luzia Corio; CIANI, Andréia Büttner. A avaliação como prática de investigação e análise da produção escrita em matemática. Revista de Educação, Campinas, v.25, p.35-45, 2008.

VIOLA DOS SANTOS, João Ricardo. Legitimidades possiveis para a formação matemática de professores de matemática (ou: assim falara Zaratustras: uma tese para todos e para ninguém). 2012. 360 f. Tese (Doutorado em Educação Matemática) - Instituto de Geociências e Ciências Exatas, Universidade Estadual Paulista, Rio Claro, 2012.

WESLEY DA SILVA, Darlysson. Conhecimentos de professores que ensinam matemática em um grupo de trabalho que analisa produções escritas em matemática. 2015. 164 f. Dissertação (Mestrado em Educação Matemática) -Universidade Federal de Mato Grosso do Sul, Campo Grande, 2015.

Enviado em 02 de junho de 2018. Aprovado em 12 de agosto de 2018. 